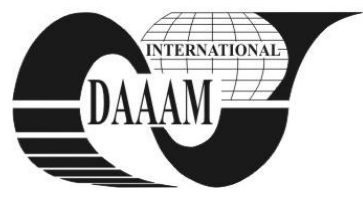

Annals of DAAAM for 2011 \& Proceedings of the 22nd International DAAAM Symposium, Volume 22, No. 1, ISSN 1726-9679 ISBN 978-3-901509-83-4, Editor B. Katalinic, Published by DAAAM International, Vienna, Austria, EU, 2011 Make Harmony between Technology and Nature, and Your Mind will Fly Free as a Bird

\title{
MODELLING OF DIAGNOSTIC AND TECHNOLOGICAL PROCESSES
}

\author{
WINKELHOEFEROVA, M[artina] \& TUPA, J[iri]
}

\begin{abstract}
The modelling of technological and diagnostic processes and appropriate methodology can be helpful in identification of critical processes in the production and in proposal of the way of innovation of these processes

The objective of this article is to focus on the modelling of processes in our research centre because these processes are very difficult and were unnoticed in our research centre and with right choice of method and software for modelling is possible to simplify and globally make easier the work with processes.

The process map is proposed and described. According to the process map, the specific process is modeled and improved thanks to application of new methodology.
\end{abstract}

Key words: diagnostic, technological process, process modelling, process map, methodology

\section{INTRODUCTION}

The process modelling is used for its simplicity and lucidity. As noted by (Hunt, 1996), it is important to have some methodical approach, be consistent and understand some basic analytical techniques. What is more difficult is to find an effective way to represent it. Most people could think up ways of drawing diagrams to represent processes but there is always problem with differences because they can come with different types of diagrams, with different types of presenting. So, it is necessary that everyone models their processes by using the same approach. Then the models can be put together and they can be understood by everyone who needs them (noted by Hunt, 1996, and Weske, 2007).

Modelling of technological and diagnostic processes is quite difficult problem because they are almost in every company and there bring the added value to the product or service. These processes are very important and very difficult also in our research centre. It is the main reason why the methodology and the process map was developed and applied for the technological and diagnostic processes in our research centre.

\section{BACKGROUND}

The technological and diagnostic processes were very difficult and unnoticed in our research center, so if someone new wanted to understand them, some competent worker had to explain every step to him/her. Therefore, the methodology was developed and the process map was prepared.

The processes in our research centre are influenced by many impacts, e.g. cleanness of environment, accuracy of measuring instruments, utilization of measuring method and mainly by handiness of workers. Defined methodology and process map make easier research and development activities which are carried out in the research centre.

The diagnostic and technological processes are very important and very difficult in our research centre. As described
(Repa, 2007), it is necessary to know how these processes work, understand them and be able to control them. These processes also have to face some kinds of risks, e.g. quality risk, technological risk and mainly personnel risk. And modelling is a good way for working with the technological and diagnostic processes because with a help of some kind of software and method it is possible to see all processes and risks which can influence it and then the processes can be optimalized.

The methodology and the process map were developed with the help of ARIS platform. As noted by (IDS Sheer), this software offers many kinds of diagrams, for example organizational diagram which describes organizational structure, eEPC diagram which serves to describing of activities and steps in specific processes or diagram of added value chain.

\section{RESULTS AND DISCUSSION}

\subsection{Methodology and process map}

Known methods and methodologies for modelling of processes were examined and it was proposed a general methodology which was applied on the technological and diagnostic processes in the research centre. It was necessary to modify characteristics from different methods and methodologies and then try to apply them on the processes in the centre. In this way, the methodology was developed for modelling of processes in the research centre. At first, the process map of these processes was prepared. This map is shown in figure 1 .

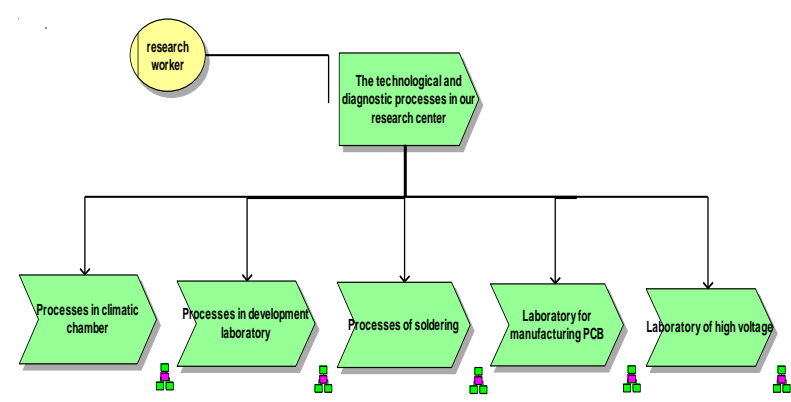

Fig. 1. The process map

The process map serves to workers, especially new workers, as a practical guide because it is necessary that everyone who works in the laboratories knows what has to do. Figure 2 shows one specific process which is carried out in the development laboratory. The figure represents the process after modelling in ARIS platform but before optimalization. 


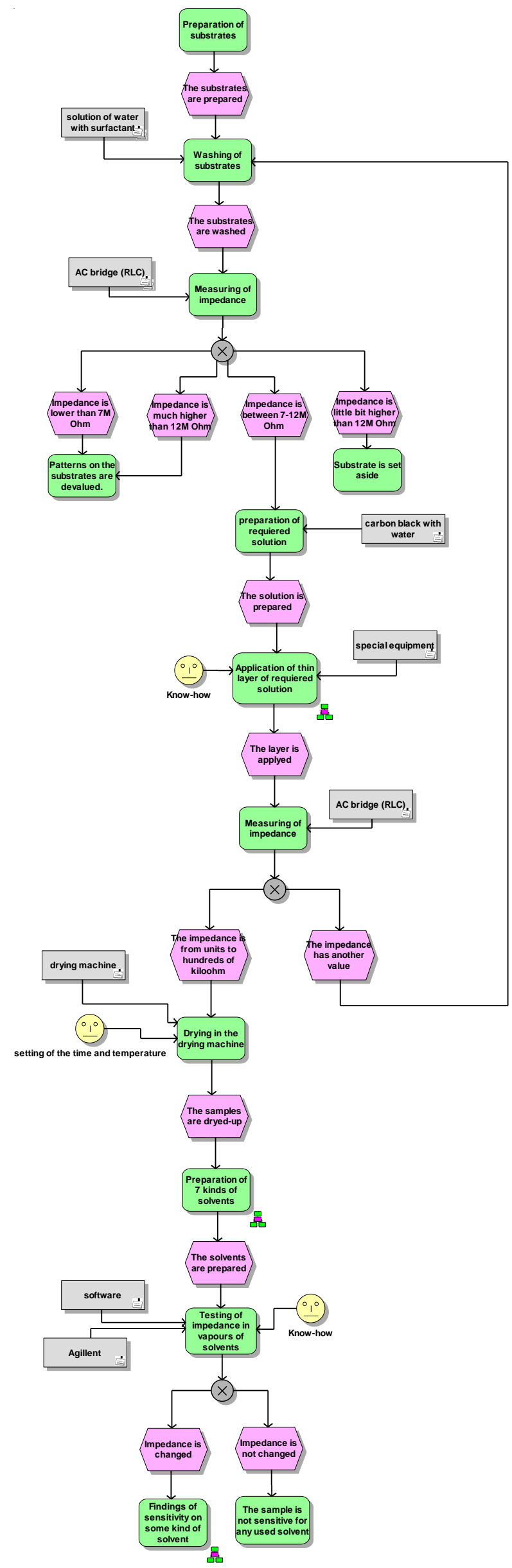

Fig. 2. Specific process in the development laboratory

\subsection{Optimalization of the process}

The process shown in figure 2 was modeled because of difficult steps which includes. As I mentioned before, the process map serves to workers as a practical guide, so the figured process (it is only example, the map includes many processes) is something like a working procedure and everyone knows what has to do. Before some competent worker had to tell to them what they have to do and helped them with it but now it is not necessary because the map describes every step in the specific process and new workers can work alone. It was the first improvement of this process - process was modelled and described and it simplified the work in the development laboratory.

As the other improvement can be considered that it was only one process, as you can see in figure 2 and it was carried out by two or three workers (one of them had to be a competent worker which knew all steps of this process). This process was divided into two processes which can run at the same time. One part is done by one worker and includes steps from the beginning to the first measuring of impedance. The second part consists of preparation of different kinds of solution and preparation of different kinds of solvents and is carried by another worker. The other steps of the process are done by both workers. It means that the third worker is not necessary here and thanks to the process map everything can be done by new workers. This improvement saves time and of course money.

The risks, which influence the processes in our research centre, were identified and it was proposed their precautions.

The proposed methodology has some limitations. It is now only a way for process analysis and description. I will focus on improvement of this methodology in my further research.

\section{CONCLUSION}

Applied methodology and process map proved that now processes are more lucid, better understandable, more transparent and the work goes quickly and the outputs are better. Everyone now can well understand all the processes which are carried out in our research centre and are included in the process map.

My future work will be dedicated to process evaluation and measurement. With it, the methodology has to be extended and improved.

\section{ACKNOWLEDGEMENTS}

This article was carried out with the support of Ministry of Education, Youth and Sports of Czech Republic, MSM 4977751310.

\section{REFERENCES}

Řepa, Václav: Podnikové Procesy - Procesní Řízení a Modelování. Publisher Grada, Praha, 2007, ISBN 80-2472252-6

Hunt, Daniel V.: Process Mapping - How to Reengineer Your Business Processes. John Wiley and Sons Ltd. (United States), 1996, ISBN 9780471132813

Weske, Mathias: Business Process Management. SpringerVerlag Berlin and Heidelberg Gmbh \& Co. Kg (Germany), 2007, ISBN: 9783540735212

Smith, Ralf F.: Business Process Management and the Balanced Scorecard. John Wiley and Sons Ltd (United Kingdom), 2007, ISBN 9780470047460

Internet website of company IDS Sheer [online]. Available on: www.ids-sheer.com 